\title{
Single Oral Dose Toxicity Test of Persicae Semen Aqueous Extracts in Mice
}

\author{
Hun-Bum Cho ${ }^{1 \#}$, Ji-Ha Park ${ }^{1 \#}$, Bu-Il Seo ${ }^{1}$, Su-Yeon Cho ${ }^{2,3}$, Kyu-Ryul Park ${ }^{2,3}$, \\ Seung-Hoon Choi ${ }^{2}$, Chang-Kyun $\mathrm{Han}^{4}$, Chang-Hyun Song ${ }^{2}$, Soo-Jin Park ${ }^{2,3}$, \\ Sae-Kwang $\mathrm{Ku}^{2,3^{*}}$
}

\section{1 : Department of Herbology, College of Oriental Medicine, Daegu Haany University}

2 : Department of Anatomy and Histology, College of Oriental Medicine, Daegu Haany University

3 : The Medical Research center for Globalization of Herbal Formulation, Daegu Haany University

4 : Department of Oriental Medicinal Materials \& Processing, College of Life Science, Kyung Hee University

\begin{abstract}
Objectives : This study was to evaluate the single dose toxicity of Persicae Semen (PS) in ICR mice. Methods : Aqueous extracts of PS (Yield $=18.60 \%$ ) were administered as an oral dose of 2,000, 1,000 and 500 $\mathrm{mg} / \mathrm{kg}$ (body weight) according to the recommendation of Korea Food and Drug Administration (KFDA) guidelines (2009-116, 2009). Animals were monitored for the mortality and changes in body weight, clinical signs and gross observation during 14 days after dosing, upon necropsy; organ weight and histopathology of 12 principle organs were examined.

Results : Amygdalin contents in PS aqueous extracts were detected as $32.50 \pm 5.96 \mu \mathrm{g} / \mathrm{ml}$. We could not find any PS extracts treatment related mortalities, clinical signs, changes on the body and organ weights, gross and histopathological observations up to $2,000 \mathrm{mg} / \mathrm{kg}$ in both female and male mice, except for transient and slight loss of locomotion detected in female and male mice treated with $2,000 \mathrm{mg} / \mathrm{kg}$. In addition, pharmacological immunomodulatory effects related findings were also demonstrated in $2,000 \mathrm{mg} / \mathrm{kg}$ treated female and male mice as hypertrophy and hyperplasia of lymphoid cells in the submandibular lymph nodes.

Conclusions : Based on the results of this experiment, the approximate lethal dose (ALD) of PS extracts after single oral treatment in female and male mice were considered above $2,000 \mathrm{mg} / \mathrm{kg}$, respectively. It should be carefully used in clinics because the possibilities of respiratory or neurological disorders were observed when administered over $2,000 \mathrm{mg} / \mathrm{kg}$ of PS extract related to amygdalin.
\end{abstract}

Key words : Persicae Semen, Single oral dose toxicity, Mouse, Amygdalin, Histopathology

\section{서 론}

Natural products are gaining space and importance in the pharmaceutical industry as well as inspiring the search for new potential sources of bioactive molecules ${ }^{1)}$. Herbs, medicinal plants and crude drug substances are considered to be a potential source of antioxidants to combat various diseases ${ }^{2)}$. However, the toxicological aspects about these natural origin-functional foods have been neglected because of the reasons that they have been used as various purposes for long times ${ }^{3)}$. Therefore, it is considered that more detail and systemic toxicological studies should be tested for control the abuse and potential toxicities even if they have been used as traditional folk medicine.

Persicae Semen (PS) is a dried seed of Prunus persica Batsch or Prunus persica Franchet var. davidiana

\footnotetext{
*Corresponding authour : Sae-kwang Ku, DVM, Ph.D. Department of Anatomy and Histology, College of Oriental Medicine,

Daegu Haany University, 290, Yugok-dong, Gyeongsan-si, Gyeongsangbuk-do, 712-715, Republic of Korea

- Tel : +82-53-819-1549 · Fax: +82-53-819-1576 $\cdot$ E-mail : gucci200@ hanmail.net

\#First authours : Hun-Bum Cho, Department of Herbology, College of Oriental Medicine, Daegu Haany University Ji-Ha Park, Department of Herbology, College of Oriental Medicine, Daegu Haany University

- Tel : +82-53-770-2263 · Fax: +82-53-768-6340 · E-mail :circle36@dhu.ac.kr

- 접수 : 2013년 4월 29일 · 수정 : 2013년 5월 22일 - 채택 : 2013년 5월 23일
} 
Maximowicz (Family: Rosaceae), and has been traditionally used as respiratory diseases including asthma, and hyperlipidemia related arthrosclerosis in Korea as single crude extract or ingredient of Korea traditional herbal prescriptions ${ }^{4)}$. Until now, various pharmacological effects of PS extracts have been experimentally studies focused on their traditional purpose like blood and cardiovascular ${ }^{5)}$, anti-asthma ${ }^{6)}$, anticancer $^{7)}$, acetylcholine esterase (ACE) inhibitory ${ }^{8)}$, neuroprotective anti-inflammatory ${ }^{9}$ activities. Especially, PS extracts potentially inhibited the ACE in rat hippocampus, and possibly ameliorating cognitions on the Alzheimer disease ${ }^{8)}$. Although favorable effects of ACE inhibitors on the Alzheimer have been suggested including seed extracts of Prunus species like $\mathrm{PS}^{8,10)}$, ACE inhibitors also showed severe toxicities ${ }^{11,12)}$; they have been used as insecticidal agent ${ }^{13)}$. In addition, one of the main chemical components of PS is also known as toxic amygdalin, source of hydrogen cyanide, which can be induced life-threaten respiratory disorders like Armeniacae Semen, a dried seed part of Prunus armeniaca Linne var. ansu Maximowicz, a well-documented toxic herb ${ }^{14)}$. In the previous study, 50\% lethal dose (LD 50$)$ of yield $19.0 \%$ Armeniacae Semen aqueous extracts after single oral administration in rats are known as $741.95 \mathrm{mg} / \mathrm{kg}^{14)}$. However, there are no detailed toxicological assessment of PS extracts has been reported even if mouse single oral dose toxicity test, except for effects on pregnant rats, in which no abnormal changes on the reproductive indices were detected after 7 days repeated oral administration of concentrated PS extracts ${ }^{4)}$.

In the present study, the amygdalin contents were observed in PS extracts by UPLC (Ultra Performance Liquid Chromatography) method, and single oral dose toxicity test of PS aqueous extracts were conducted in mice according to the Korea Food and Drug Administration (KFDA) Guidelines ${ }^{15)}$ to obtain the primary safety information about PS and further clarifies their safety for clinical use.

\section{MATERIALS AND METHODS}

\section{Preparation of PS aqueous extracts}

Aqueous PS (yield $=18.60 \%$ ) extracts were prepared by routine methods using rotary vacuum evaporator (Buchi Rotavapor R-144, Switzerland) and programmable freeze dryer (Freezone 1; Labconco Corp., USA) from dried seeds of Prunus persica Franchet var. davidiana Maximowicz, produced in China (Family: Rosaceae), which were purchased from Ominiherb (Korea) after confirm the morphology under microscopy. The voucher specimens documenting this purchase were deposited in the herbarium of the Medical Research center for Globalization of Herbal Formulation, Daegu Haany University. In the present study, prepared herbs were boiled at $80^{\circ} \mathrm{C}, 3 \mathrm{hrs}$ and then, evaporated and lysophilized. Powders of PS extracts are light brown powder, and all extracts were stored in a refrigerator at $-20^{\circ} \mathrm{C}$ to protect from light and degeneration until use. They were well soluble up to $100 \mathrm{mg} / \mathrm{ml}$ concentration levels in distilled water used as vehicle as clear light brown solution.

\section{Measurement of amygdalin contents in} PS extracts by UPLC

\section{1) Chromatography conditions}

The UPLC system (Waters, USA), equipped with a pump Waters ACQUITY ${ }^{\mathrm{TM}}$ ultra performance LC system (Waters, USA) and a Waters ACQUITY ${ }^{\mathrm{TM}}$ photodiode array detector (PDA), was used for analysis. The Empower Data System was used for recording of the output signal of the detector. A Waters ACQUITY ${ }^{\mathrm{TM}}$ $\mathrm{BEH}$ C18column $(1.7 \mu \mathrm{m}, 2.1 \times 100 \mathrm{~mm})$ was used for separation. The mobile phase was composed of $0.1 \%$ formic acid water and $0.1 \%$ formic acid acetonitrile (Sigma, USA) with the gradient elution system at a flow rate of $0.4 \mathrm{ml} / \mathrm{min}$. The injection volume was 2 $\mu \mathrm{L}$. The detection UV wavelength was set at $254 \mathrm{~nm}$. The column temperature was set at room temperature.

\section{2) Preparation of standard solutions and sample}

Standard stock solutions of amygdalin (Wako, Japan) were prepared by dissolving at a concentration of $1000 \mathrm{mg} / \mathrm{mL}$ in $10 \mathrm{~mL}$ of methanol. Working standard solutions were made by diluting the standard stock solution with methanol. Standard stock solutions and working solutions were stored at $4^{\circ} \mathrm{C}$. For preparation of sample, the extract of PS was weighed and dissolved in methanol at a concentration of $10 \mathrm{mg} / \mathrm{mL}$. Before UPLC analysis, the sample preparation was filtered through a $0.22 \mu \mathrm{m}$ filter. Amygdalin contents were expressed as mean $\pm \mathrm{SD}$ of three independent measurements as $\mu \mathrm{g} / \mathrm{ml}$, in this experiment.

\section{Experimental Animals and administration}

\section{of PS extracts}

Each of twenty female and male ICR mice (6-wk old upon receipt, SLC, Japan) was used after 
acclimatization for 7 days. Animals were allocated five per polycarbonate cage in a temperature $\left(20-25^{\circ} \mathrm{C}\right)$ and humidity (40-45\%) controlled room. Light dark cycle was $12 \mathrm{hr}$ and feed (Samyang, Korea) and water were supplied free to access. All animals were overnight fasted (about 18hrs) before dosing and terminal necropsy. Animals were marked by picric acid. This study was carried out according to the guidelines of the Animal Ethical Committee, The University of Daegu Haany University (Korea). PS have been used as Korean medicine as an ingredient of herbal formula for long times and no revealed toxicological data was available, the highest dosage level was selected as $2,000 \mathrm{mg} / \mathrm{kg}$ according to the recommended by KFDA Guidelines (2005), the limited dosages, and 1,000 and $500 \mathrm{mg} / \mathrm{kg}$ was selected using common ratio 2 . In addition, a vehicle control group was added. Animal was once orally administered using a sonde attached to a syringe of $1 \mathrm{ml}$ after overnight fasting (about $18 \mathrm{hr}$, water was not restricted), at a dosage volume of $20 \mathrm{ml} / \mathrm{kg}$. Feed and water were restricted further for about $3 \mathrm{hrs}$ after end of administration.

\section{Abnormal behavior, clinical sign and body}

\section{weight}

All abnormal clinical signs and behaviors were recorded before and after dosing at least twice a day based on the functional observational battery test ${ }^{16,17)}$. Body weights were measured on the day of administration (Day 0) prior to treatment, 1, 2, 7, 13 and 14 days after dosing, respectively.

\section{Necropsy}

All unscheduled died animals were grossly observed immediately after finding them and all survived animals were subjected to terminal necropsy. Animals were asphyxiated by carbon dioxide and gross necropsy was performed in all animals at Day 14 after overnight fasting (about $18 \mathrm{hrs}$, water was not restricted).

\section{Organ weight measurements and sampling}

The absolute organ weight was measured and then relative organ weight (\% for body weight) was calculated. The following organs were collected for histopathological observation. Measured and sampled organs: lung, heart, thymus, left kidney, left adrenal gland, spleen, left testis or ovary, liver, splenic lobe of pancreas, prostate, urinary bladder, left epididymis or total uterus and left submandibular lymph node.

\section{Histopathology}

Samples were fixed in $10 \%$ neutral buffered formalin. After $18 \mathrm{hrs}$ of fixation, paraffin embedding was conducted and $4 \mu \mathrm{m}$ sections were prepared by routine histological methods. Representative sections of each specified organs were stained with hematoxylin-eosin for light microscopical examination.

\section{Statistical analyses}

Multiple comparison tests for different dose groups were conducted. Variance homogeneity was examined using the Levene test ${ }^{18)}$. If the Levene test indicated no significant deviations from variance homogeneity, the obtain data were analyzed by one way ANOVA test followed by Scheffe test to determine which pairs of group comparison were significantly different. In case of significant deviations from variance homogeneity were observed at Levene test, a non-parametric comparison test, the Mann-Whitney U (MW) test was conducted to determine the specific pairs of group comparison, which are significantly different ${ }^{19)}$.

Statistical analyses were conducted using SPSS for Windows (Release 14.0K, SPSS Inc., USA) and a $p$-value of less than 0.05 was considered to be a significant difference. In addition, degree of clinical signs, gross and histopathological findings were subdivided into 3 degrees: $3+$ Severe, 2+ moderate, $1+$ slight, according to the previous reports ${ }^{3,20)}$.

\section{RESULTS}

\section{Analysis of amygdalin}

Determination of amygdalin in PS extracts was established by the use of the UPLC system. Contents of the amygdalin were calculated from the calibration curve of the standards (Fig 1). Validation of the method verified its reliability and stability. Use of the method resulted in successive separation of amygdalin in PS samples. Amygdalin contents in PS extracts were determined as $32.50 \pm 5.96 \mu \mathrm{g} / \mathrm{ml}$ in this study.

(A)

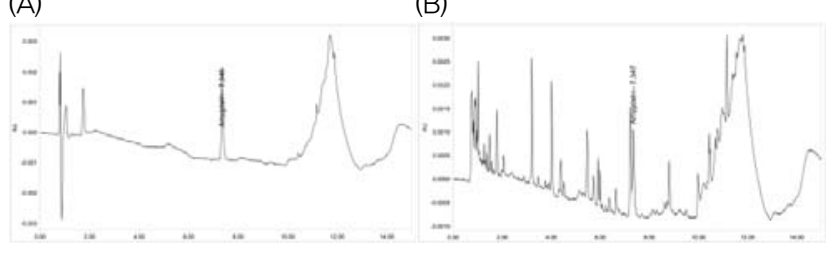

Fig. 1. UPLC chromatogram of amygdalin in PS. UPLC chromatogram of commercial standard amygdalin (A). UPLC chromatogram of amygdalin in PS (B). The chromatograms were obtained at $254 \mathrm{~nm}$. PS $=$ Persicae Semen aqueous extracts 


\section{Mortalities}

No unscheduled or PS extract-treat related mortalities were detected in all dose levels tested in this study, and accordingly all of animals $(5 / 5 ; 100 \%)$ including both female and male vehicle control mice were subjected to the terminal necropsy in this study (Table 1).

Table 1. Mortality, clinical signs, gross and histopathological findings of animals exposed with PS in the single dose toxicity study

\begin{tabular}{|c|c|c|c|c|c|c|c|c|}
\hline \multirow[t]{2}{*}{ Groups } & \multirow{2}{*}{$\begin{array}{c}\text { Male } \\
\text { vehicle } \\
\text { control }\end{array}$} & \multicolumn{3}{|c|}{$\begin{array}{l}\text { PS treated male } \\
\text { rats }(\mathrm{mg} / \mathrm{kg})\end{array}$} & \multirow{2}{*}{$\begin{array}{l}\text { Female } \\
\text { vehicle } \\
\text { control }\end{array}$} & \multicolumn{3}{|c|}{$\begin{array}{l}\text { PS treated female } \\
\text { rats }(\mathrm{mg} / \mathrm{kg})\end{array}$} \\
\hline & & 2,000 & 1,000 & 500 & & 2,000 & 1,000 & 500 \\
\hline Mortality & $0 / 5$ & $0 / 5$ & $0 / 5$ & $0 / 5$ & $0 / 5$ & $0 / 5$ & $0 / 5$ & $0 / 5$ \\
\hline \multicolumn{9}{|l|}{ Clinical signs } \\
\hline Loss of locomotion & $0 / 5$ & $5 / 5$ & $0 / 5$ & $0 / 5$ & $0 / 5$ & $5 / 5$ & $0 / 5$ & $0 / 5$ \\
\hline \multicolumn{9}{|l|}{ Gross findings } \\
\hline Lung focal congestion & $1 / 5$ & $1 / 5$ & $1 / 5$ & $1 / 5$ & $1 / 5$ & $1 / 5$ & $1 / 5$ & $1 / 5$ \\
\hline Thymus atrophy & $1 / 5$ & $0 / 5$ & $0 / 5$ & $0 / 5$ & $1 / 5$ & $0 / 5$ & $0 / 5$ & $0 / 5$ \\
\hline Spleen atrophy & $1 / 5$ & $0 / 5$ & $0 / 5$ & $0 / 5$ & $1 / 5$ & $0 / 5$ & $1 / 5$ & $0 / 5$ \\
\hline Spleen hypertrophy & $1 / 5$ & $0 / 5$ & $1 / 5$ & $1 / 5$ & $1 / 5$ & $1 / 5$ & $1 / 5$ & $0 / 5$ \\
\hline Lymph node hypertrophy ${ }^{\text {a) }}$ & $1 / 5$ & $3 / 5$ & $2 / 5$ & $2 / 5$ & $0 / 5$ & $3 / 5$ & $2 / 5$ & $1 / 5$ \\
\hline Uterus edema & & & & & $3 / 5$ & $1 / 5$ & $2 / 5$ & $3 / 5$ \\
\hline \multicolumn{9}{|l|}{ Histopathological findings } \\
\hline Lung focal congestion & $1 / 5$ & $1 / 5$ & $1 / 5$ & $1 / 5$ & $1 / 5$ & $1 / 5$ & $1 / 5$ & $1 / 5$ \\
\hline Thymus cDE ${ }^{b)}$ & $1 / 5$ & $0 / 5$ & $0 / 5$ & $0 / 5$ & $1 / 5$ & $0 / 5$ & $1 / 5$ & $0 / 5$ \\
\hline Thymus focal congestion & $0 / 5$ & $0 / 5$ & $1 / 5$ & $0 / 5$ & $1 / 5$ & $1 / 5$ & $0 / 5$ & $0 / 5$ \\
\hline Spleen $\mathrm{rHP}^{\mathrm{c})}$ & $1 / 5$ & $0 / 5$ & $1 / 5$ & $0 / 5$ & $1 / 5$ & $0 / 5$ & $0 / 5$ & $0 / 5$ \\
\hline Liver focal inflammation & $1 / 5$ & $1 / 5$ & $1 / 5$ & $1 / 5$ & $0 / 5$ & $0 / 5$ & $0 / 5$ & $0 / 5$ \\
\hline Liver focal fatty changes & $1 / 5$ & $0 / 5$ & $0 / 5$ & $1 / 5$ & $0 / 5$ & $0 / 5$ & $0 / 5$ & $1 / 5$ \\
\hline Lymph node $\mathrm{HP}^{\text {ad) }}$ & $0 / 5$ & $3 / 5$ & $0 / 5$ & $1 / 5$ & $1 / 5$ & $4 / 5$ & $0 / 5$ & $2 / 5$ \\
\hline
\end{tabular}

Values were observed animals/total observed animals

PS $=$ Persicae Semen aqueous extracts

a) Submandibular lymph node

b) Cortex lymphoid cell decreases

c) Red pulp lymphoid cell hyperplasia

d) Diffused hyperplasia of lymphoid cells

\section{Clinical signs}

In this study, no PS extracts treatment related abnormal clinical signs were observed during 14 days observation periods regardless of male and female mice, except for loss of locomotion, which were detected in all five $(5 / 5 ; 100 \%)$ female and male mice treated with PS extracts $2,000 \mathrm{mg} / \mathrm{kg}$ restricted to the treatment day. Loss of locomotion sign was detected from immediately after end of administration, and they were disappeared within 30min after end of treatment in this experiment (Table 1).

\section{Changes on body weights}

No significant changes in body weight were detected in all dose levels tested in the present study as compared with male vehicle control mice, respectively (Fig 2).
(A)

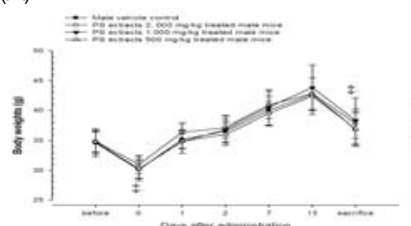

(B)

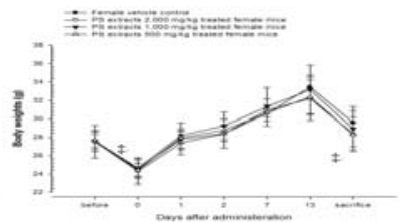

Fig. 2. Changes on the body weights during 14 days of observation in female and male rats after single oral treatment of PS extracts. No significant changes on body weights were detected in all PS extract treated rats as compared with equal genders of vehicle control rats, respectively. Values are expressed as mean $\pm S D$ of five mice. PS = Persicae Semen aqueous extracts. $\neq$, all rats were overnight fasted; before means 1 day before administration. 0 means the day of administration.

\section{Changes on the organ weights}

No meaningful changes on the principle organ weights were observed in all PS extracts treated female and male mice as compared with each equal gender of vehicle control, except for significant $(p<0.05)$ increases of submandibular lymph node weights restricted to 2,000 $\mathrm{mg} / \mathrm{kg}$ of PS extracts treated male mice as compared with equal genders of vehicle control mice, in this experiment (Table 2).

Table 2. Relative organ weights of animals exposed with PS in the single dose toxicity study

\begin{tabular}{|c|c|c|c|c|c|c|c|c|}
\hline \multirow{2}{*}{ Groups } & \multirow{2}{*}{$\begin{array}{l}\text { Male vehicle } \\
\text { control }\end{array}$} & \multicolumn{3}{|c|}{ PS treated male rats $(\mathrm{mg} / \mathrm{kg})$} & \multirow{2}{*}{$\begin{array}{l}\text { Female vehicle } \\
\text { control }\end{array}$} & \multicolumn{3}{|c|}{ PS treated female rats $(\mathrm{mg} / \mathrm{kg})$} \\
\hline & & 2,000 & 1,000 & 500 & & 2,000 & 1,000 & 500 \\
\hline \multicolumn{9}{|c|}{ Organ weights (\% of body weight) } \\
\hline Lung & $0.53 \pm 0.06$ & $0.52 \pm 0.02$ & $0.53 \pm 0.04$ & $0.56 \pm 0.03$ & $0.57 \pm 0.03$ & $0.59 \pm 0.04$ & $0.59 \pm 0.03$ & $0.58 \pm 0.04$ \\
\hline Heart & $0.47 \pm 0.02$ & $0.45 \pm 0.04$ & $0.46 \pm 0.05$ & $0.46 \pm 0.04$ & $0.47 \pm 0.04$ & $0.48 \pm 0.01$ & $0.45 \pm 0.03$ & $0.50 \pm 0.09$ \\
\hline Thymus & $0.14 \pm 0.03$ & $0.15 \pm 0.03$ & $0.16 \pm 0.02$ & $0.16 \pm 0.03$ & $0.20 \pm 0.03$ & $0.23 \pm 0.05$ & $0.18 \pm 0.04$ & $0.21 \pm 0.05$ \\
\hline Kidney (left) & $0.76 \pm 0.11$ & $0.77 \pm 0.08$ & $0.79 \pm 0.11$ & $0.85 \pm 0.12$ & $0.64 \pm 0.06$ & $0.68 \pm 0.02$ & $0.66 \pm 0.06$ & $0.66 \pm 0.04$ \\
\hline Adrenal gland (left) & $0.01 \pm 0.01$ & $0.01 \pm 0.01$ & $0.01 \pm 0.01$ & $0.01 \pm 0.01$ & $0.02 \pm 0.01$ & $0.03 \pm 0.01$ & $0.23 \pm 0.01$ & $0.02 \pm 0.01$ \\
\hline Spleen & $0.32 \pm 0.02$ & $0.34 \pm 0.05$ & $0.33 \pm 0.03$ & $0.32 \pm 0.03$ & $0.43 \pm 0.09$ & $0.47 \pm 0.01$ & $0.42 \pm 0.10$ & $0.42 \pm 0.06$ \\
\hline Testis/Ovary (left) & $0.32 \pm 0.04$ & $0.32 \pm 0.02$ & $0.32 \pm 0.03$ & $0.33 \pm 0.04$ & $0.07 \pm 0.01$ & $0.09 \pm 0.03$ & $0.09 \pm 0.02$ & $0.10 \pm 0.03$ \\
\hline Liver & $4.21 \pm 0.13$ & $4.09 \pm 0.15$ & $4.22 \pm 0.44$ & $4.34 \pm 0.18$ & $4.20 \pm 0.44$ & $4.07 \pm 0.09$ & $4.33 \pm 0.47$ & $4.45 \pm 0.39$ \\
\hline Pancreas & $0.47 \pm 0.03$ & $0.48 \pm 0.04$ & $0.45 \pm 0.09$ & $0.47 \pm 0.03$ & $0.55 \pm 0.07$ & $0.54 \pm 0.06$ & $0.53 \pm 0.05$ & $0.51 \pm 0.07$ \\
\hline Brain & $1.29 \pm 0.12$ & $1.26 \pm 0.08$ & $1.26 \pm 0.14$ & $1.28 \pm 0.05$ & $1.61 \pm 0.09$ & $1.63 \pm 0.10$ & $1.71 \pm 0.12$ & $1.65 \pm 0.11$ \\
\hline Epididymis (left)/Uterus & $0.12 \pm 0.02$ & $0.11 \pm 0.02$ & $0.11 \pm 0.02$ & $0.11 \pm 0.02$ & $0.57 \pm 0.18$ & $0.44 \pm 0.10$ & $0.50 \pm 0.27$ & $0.58 \pm 0.27$ \\
\hline Lymph node (left) a) & $0.01 \pm 0.01$ & $0.03 \pm 0.01^{*}$ & $0.01 \pm 0.01$ & $0.02 \pm 0.01$ & $0.02 \pm 0.01$ & $0.03 \pm 0.02$ & $0.02 \pm 0.01$ & $0.02 \pm 0.01$ \\
\hline
\end{tabular}

Values are expressed as mean \pm S.D. of five mice

PS $=$ Persicae Semen aqueous extracts

a) Submandibular lymph node

$\mathrm{p}<0.05$ as compared with equal genders of vehicle control by MW test 


\section{Necropsy findings}

Although slight and lower frequencies of hypertrophy of submandibular lymph nodes were also demonstrated in female and male vehicle control mice, marked increase trends of the frequency of hypertrophy at gross inspections on the submandibular lymph node were observed in $2,000 \mathrm{mg} / \mathrm{kg}$ treated female and male mice as compared with equal genders of vehicle control, in this study. In addition, some sporadic findings such as slight congestion spots of lung, atrophy of thymus, spleen atrophy or hypertrophy and edematous changes of uterus were sporadically detected throughout all experimental groups tested in this study including both gender of vehicle control, respectively (Table 1).

\section{Histopathological findings}

Marked increase trends of the frequency of hyperplasia of lymphoid cells at histopathological observations on the submandibular lymph node (Fig 3) were also detected in $2,000 \mathrm{mg} / \mathrm{kg}$ treated female and male mice as compared with equal genders of vehicle control, in which slight and lower frequencies of diffused lymphoid cell hyperplasia were demonstrated. In addition, some sporadic findings such as slight hypertrophy of lung alveolus wall with focal hemorrhage, congestion or decreases of lymphoid cells in the cortex of thymus, hyperplasia of lymphoid cells in the red pulp of spleen and focal fatty changes or focal inflammatory cell infiltration in the liver were sporadically detected throughout all experimental groups tested in the present study including both gender vehicle controls, respectively (Table 1 ).

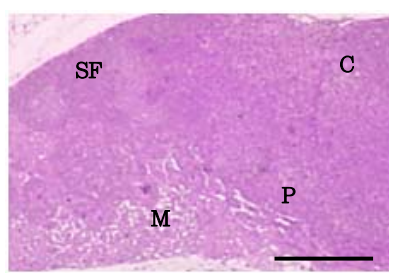

Female vehicle control

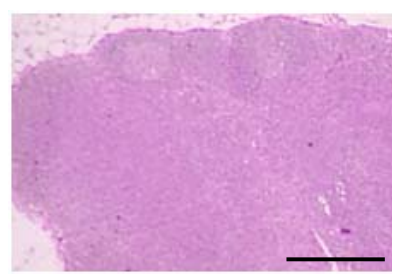

$2,000 \mathrm{mg} / \mathrm{kg}$ treated female

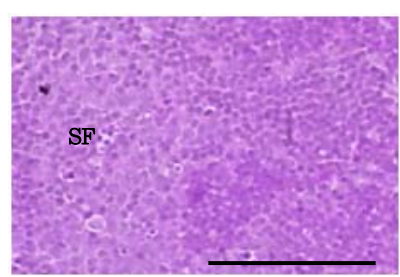

HP 1+

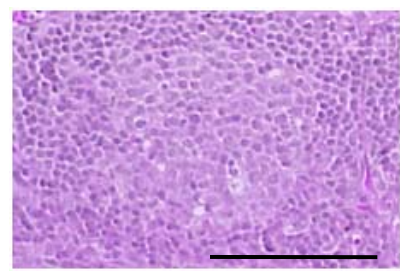

HP $1+$

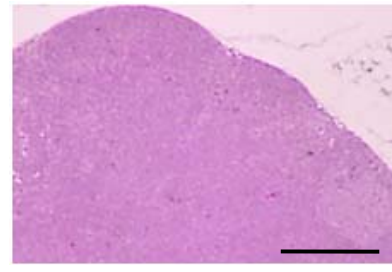

$1,000 \mathrm{mg} / \mathrm{kg}$ treated male

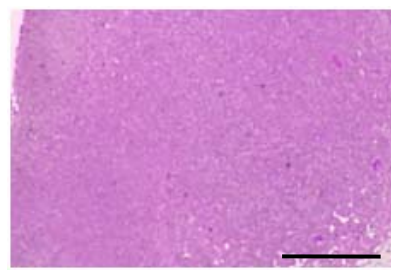

$500 \mathrm{mg} / \mathrm{kg}$ treated male

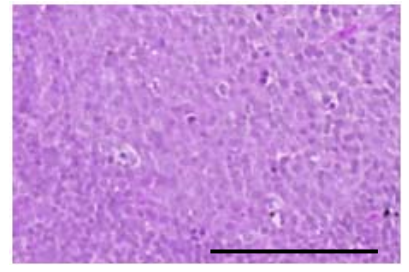

HP 1+

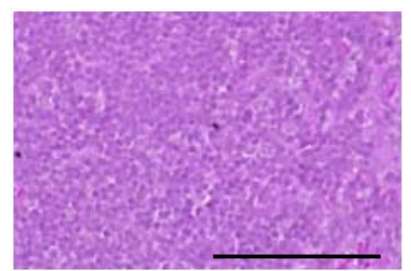

HP 1+
Fig. 3. Representative histopathological changes detected on the submandibular lymph node after single oral treatment of PS aqueous extracts. Note that marked increase trends of the frequency of hyperplasia of lymphoid cells (HP) at histopathological observations on the submandibular lymph node were detected in $2,000 \mathrm{mg} / \mathrm{kg}$ treated female and male mice as compared with equal genders of vehicle control, in which slight and lower frequencies of diffused lymphoid cell hyperplasia were demonstrated. These findings are considered as related to the pharmacological immunomodulatory effects of PS extracts, rather than toxicological signs. C, cortex; P, paracortex; M, medullary sinus; SF, secondary lymphatic follicle; PS = Persicae Semen aqueous extracts; All Hematoxylin \& Eosin stain; Histopathological findings were subdivided into 3 degrees: $3+$ Severe, 2+ moderate, $1+$ slight.Scale bars $=80 \mu \mathrm{m}$.

\section{DISCUSSION}

Aqueous extracts of PS have been traditionally used as various respiratory diseases including asthma, and hyperlipidemia related arthrosclerosis in Korea as single crude extract or ingredient of Korea traditional herbal prescriptions ${ }^{4)}$ and it has been well-documented that PS has various potent pharmacological effects including blood and cardiovascular, anti-asthma anticancer, ACE inhibitory and neuro-protective anti-inflammatory activities ${ }^{5,6,8,9)}$, but there are no detailed toxicological assessment of PS extracts has been trials even if mouse single oral dose toxicity test, except for effects on pregnant rats ${ }^{4}$. Favorable effects of ACE inhibitors on the Alzheimer have been suggested $^{8,10)}$, but controversially, ACE inhibitors also showed severe toxicities ${ }^{11,12)}$ and they have been used as insecticidal agent ${ }^{13)}$. In addition, one of the main chemical components of PS is also known as toxic amygdalin source of hydrogen cyanide. In the present study, we investigated the single oral dose toxicity of PS aqueous extracts on the mice as a part of the safety test with amygdalin contents. In order to observe $\mathrm{LD}_{50}$, test substances were administered orally to female and male mice at dose levels of 2,000, 
1,000 and $500 \mathrm{mg} / \mathrm{kg}$.

In KFDA Guidelines ${ }^{15)}$, the recommended highest dose of test materials were $2,000 \mathrm{mg} / \mathrm{kg}$ or the maximum solubility, and they also recommended that in case of single dose toxicity in mouse, the dosage volume were below $20 \mathrm{ml} / \mathrm{kg}$. In the present study, the highest dosage was selected as $2,000 \mathrm{mg} / \mathrm{kg}$ in a volume of $20 \mathrm{ml} / \mathrm{kg}$, the recommended oral dose volume in mice and the limited highest dosages recommended by KFDA Guidelines, and 1,000 and $500 \mathrm{mg} / \mathrm{kg}$ are selected using common ratio 2 . In addition, each female and male vehicle control groups were added. Test material was orally administered using distilled water as vehicle in this study.

Amygdalin contents in PS extracts were determined as $32.50 \pm 5.96 \mu \mathrm{g} / \mathrm{ml}$ in this study, and we could not find any PS extracts treatment related mortalities, clinical signs, changes on the body and organ weights, gross and histopathological observations against 14 principle organs up to $2,000 \mathrm{mg} / \mathrm{kg}$ in both female and male mice after single oral administration of PS extracts, except for transient and slight loss of locomotion restrictly detected at treatment day (within 30min after end of administration) in female and male mice treated with $2,000 \mathrm{mg} / \mathrm{kg}$, significant $(\mathrm{p}<0.05)$ increases of the submandibular lymph node weights in 2,000 $\mathrm{mg} / \mathrm{kg}$ treated male mice with increase trends of the frequency of hypertrophy at gross inspections and of hyperplasia of lymphoid cells at histopathological observations on the submandibular lymph node in $2,000 \mathrm{mg} / \mathrm{kg}$ treated female and male mice.

In this experiment, no PS aqueous extracts treatment related mortalities were demonstrated up to 2,000 $\mathrm{mg} / \mathrm{kg}$ quite differed from the results of the previous single oral dose toxicity test of yield $19.0 \%$ Armeniacae Semen, similar dried seed parts of Prunus species containing amygdalin aqueous extracts in $\operatorname{rats}^{14)}$, in which all of five rats treated 2,000 and $500 \mathrm{mg} / \mathrm{kg}$ were died within treatment day, and $\mathrm{LD}_{50}$ was detected as $741.95 \mathrm{mg} / \mathrm{kg}$. These differences are considered as results of different animal species or amygdalin contents. It is generally known that amygdalin, source of hydrogen cyanide, which can be induced life-threaten respiratory disorders ${ }^{14,21)}$. Therefore, more detail studies like toxicity test of PS extracts in various animal species were should be further succeeded to elucidate this point.

Transient and slight loss of locomotion, restrictly detected at treatment day in all $(5 / 5 ; 100 \%)$ female and male mice treated with PS extracts $2,000 \mathrm{mg} / \mathrm{kg}$ were considered as treatment related toxicological signs related to amygdalin related respiratory disorders or ACE inhibitory neurological effects because similar clinical sign has been also observed in of the previous single oral dose toxicity test of yield 19.0\% Armeniacae Semen as depress of respirations ${ }^{14)}$ and in various ACE inhibitors as one of obvious neuropsychiatric signs $^{11,12,22)}$.

However, these possibilities that respiratory or neurological disorders can be disregard in clinical use because they are transient in the highest dosages female and male only, and recovered to normal within $30 \mathrm{~min}$ after end of administration in this experiment.

All animals including $2,000 \mathrm{mg} / \mathrm{kg}$ treated female and male mice used in this study shows normal body weight increases and organ weights ranged in age-matched reference mice ${ }^{23)}$, except for significant $(p<0.05)$ increases of the submandibular lymph node weights in 2,000 $\mathrm{mg} / \mathrm{kg}$ treated male mice. Although slight and lower frequencies of hypertrophy of submandibular lymph nodes and diffused lymphoid cell hyperplasia were also demonstrated in female and male vehicle control mice, marked increase trends of the frequency of hypertrophy at gross inspections and of hyperplasia of lymphoid cells at histopathological observations on the submandibular lymph node were also detected in $2,000 \mathrm{mg} / \mathrm{kg}$ treated female and male mice as compared with equal genders of vehicle control, in this study. These signs are considered as related to the pharmacological immunomodulatory effects of PS aqueous extracts, not toxicological signs. Generally, hyperplasia of lymphoid cells and related hypertrophy of lymph nodes were observed after treatment of immunomodulatory agents ${ }^{24)}$.

The slight congestion spots of lung, atrophy of thymus, spleen atrophy or hypertrophy and edematous changes of uterus detected in the present study as gross findings, and hypertrophy of lung alveolus wall with focal hemorrhage, decreases of lymphoid cells in the cortex of thymus, congestions of thymus, hyperplasia of lymphoid cells in the red pulp of spleen and focal fatty changes or focal inflammatory cell infiltration in the liver as histopathological findings were considered as accidental findings not toxicological signs related to the PS extracts treatment because they were sporadically detected throughout experimental groups tested in the present study including both genders of vehicle control. Especially, the edematous changes in uterus were considered as secondary changes from different physiological estrus cycles ${ }^{25)}$.

\section{CONCLUSIONS}

1. Because no PS extracts treatment related mortalities were detected up to $2,000 \mathrm{mg} / \mathrm{kg}$ in both male and female mice in the present study, the approximate 
lethal dose of PS extracts after single oral treatment in female and male mice were considered above $2,000 \mathrm{mg} / \mathrm{kg}$, respectively.

2. However, it also observed that the possibilities of respiratory or neurological disorders, like loss of locomotion when administered over $2,000 \mathrm{mg} / \mathrm{kg}$ of PS extracts in the present study.

3. In addition, pharmacological immunomodulatory effects related findings were also demonstrated in 2,000 $\mathrm{mg} / \mathrm{kg}$ treated female and male mice.

\section{Acknowledgement}

This work was supported by the National Research Foundation of Korea (NRF) grant funded by the Korea government [MEST] (No.2012-0009400).

\section{REFERENCES}

1. Devipriya N, Srinivasan M, Sudheer AR, Menon VP. Effect of ellagic acid, a natural polyphenol, on alcohol-induced prooxidant and antioxidant imbalance: a drug dose dependent study. Singapore Med J. 2007 ; 48(4) : 311-8.

2. Noh JR, Kim YH, Gang GT, Hwang JH, Kim SK, Ryu SY, Kim YS, Lee HS, Lee CH. Hepatoprotective effect of Platycodon grandiflorum against chronic ethanol-induced oxidative stress in C57BL/6 mice. Ann Nutr Metab. 2011 ; 58(3) : 224-31.

3. Roh SS, SK Ku. Mouse single oral dose toxicity study of DHU001, a polyherbal formula. Toxicol Res. 2010 ; 26 : 53-9.

4. Seo BI. Effect of Leonuri Sibirici Herba and Pruni Persicae Semen on pregnant rats. Kor J Herbology. $2011 ; 26$ : 47-52.

5. Wang N, Liu Q, Peng D, Wang L, Wang S. Experimental study on anti-thrombus effect of different extracts from Semen Persicae. Zhong Yao Cai. 2002 ; 25 : 414-5.

6. Zhang YB, Qin F, Sun HX. Immunosuppressive activity of Semen Persicae ethanol extract on specific antibody and cellular response to ovalbumin in mice. Chem Biodivers. 2006 ; 3 : 967-74.

7. Kwon HY, Hong SP, Hahn DH, Kim JH. Apoptosis induction of Persicae Semen extract in human promyelocytic leukemia (HL-60) cells. Arch Pharm Res. 2003 ; 26 : 157-61.

8. Kim YK, Koo BS, Gong DJ, Lee YC, Ko JH, Kim CH. Comparative effect of Prunus persica L. BATSCH-water extract and tacrine (9-amino-1,2,3,4-tetrahydroacridine hydrochloride) on concentration of extracellular acetylcholine in the rat hippocampus. J Ethnopharmacol. 2003 ; 87 : 149-54.

9. Yang HY, Chang HK, Lee JW, Kim YS, Kim H, Lee MH, Shin MS, Ham DH, Park HK, Lee H, Kim CJ. Amygdalin suppresses lipopolysaccharide-induced expressions of cyclooxygenase-2 and inducible nitric oxide synthase in mouse BV2 microglial cells. Neurol Res.2007;29 : S59-64.

10. Kulkarni KS, Kasture SB, Mengi SA. Efficacy study of Prunus amygdalus (almond) nuts in scopolamine-induced amnesia in rats. Indian $\mathrm{J}$ Pharmacol. 2010 ; 42 : 168-73.

11. Allegri RF, Guekht A. Cerebrolysin improves symptoms and delays progression in patients with Alzheimer's disease and vascular dementia. Drugs Today (Barc). $2012 ; 48: 25-41$.

12. Corbett A, Smith J, Ballard C. New and emerging treatments for Alzheimer's disease. Expert Rev Neurother. 2012 ; 12 : 535-43.

13. Kovacic P, Somanathan R. Propoxur: a novel mechanism for insecticidal action and toxicity. Rev Environ Contam Toxicol. 2012 ; 218 : 141-50.

14. Kim SR, Lee JW, Lim SY, Jung YS, Choi HY, Kim JD. Rat single oral dose toxicity test of Armeniacae Semen (including endocarp). Korean J Orient Int Med. 2012 ; 33 : 145-59.

15. Korea Food and Drug Administration. Testing Guidelines for Safety Evaluation of Drugs. 2009. (Notification No. 2009-116, issued by the Korea Food and Drug Administration on August 24, 2009, Seoul, Korea).

16. Irwin $\mathrm{S}$. Comprehensive observational assessment: Ia. A systematic, quantitative procedure for assessing the behavioral and physiologic state of the mouse. Psychopharmacology. $1968 ; 13$ : 222-57.

17. Dourish CT. Effects of drugs on spontaneous motor activity. In: Experimental Psychopharmacology (Greenshaw AJ, Dourish CT, eds). Clifton, USA: Humana Press. 1987 : 325-34.

18. Levene A. Pathological factors influencing excision of tumours in the head and neck. Part I. Clin Otalary. $1981 ; 6: 145-51$

19. Ludbrook J. Update: microcomputer statistics packages. A personal view. Clin Exp Pharmacol Physiol. 1997 ; $24: 294-96$.

20. Lee WH, Gam CO, Ku SK, Choi SH. Single oral dose toxicity test of platycodin $\mathrm{D}$, a saponin from platycodin radix in mice. Toxicol Res. 2011 ; 27 : 217-24.

21. Seo BI, Park JH. A philological study on poisoning of Armeniacae Amarum Semen. J Jeahan Orient Med Acad. 2008 ; 6 : 135-62. 
22. Pohanka M. Acetylcholinesterase inhibitors: a patent review (2008-present). Expert Opin Ther Pat. 2012 ; 22 : 871-86.

23. Yamauchi C, Fujita S, Obara T, Ueda T. Effects of room temperature on reproduction, body weight and organ weights, food and water intakes, and hematology in mice. Exp Anim. 1983 ; 32 : 1-11.

24. Lee HS, Yang KJ, Shin HD, Park BR, Son CW, Jang HJ, Park DC, Jung YM, Ku SK. Single oral dose toxicity studies of Polycan, a $\beta$-glucan originated from Aureobasidium in mice. Toxicol Res. 2005 ; 21 : 361-65.

25. Pineda $\mathrm{MH}$. Female reproductive system. In: Veterinary endocrinology and reproduction (McDonald LE, Pineda MH, eds). Philadelphia, USA: Lea \& Febiger. 1989 : 303-54. 